\title{
NATURALEZA Y FUNCIÓN DE LA LITERATURA EN LA POÉTICA EXPLÍCITA DE CARLOS PUJOL
}

\author{
LITERATURE'S NATURE AND FUNCTION \\ ACCORDING TO CARLOS PUJOL'S EXPLICIT POETICS
}

\author{
Teresa VALLÈS BOTEY \\ Universitat Internacional de Catalunya \\ tvalles@uic.es
}

Resumen: Para contribuir a la comprensión del pensamiento literario del poeta, novelista, crítico y traductor Carlos Pujol (1936-2012) se examinan tres fuentes primarias de su poética, donde de forma explícita - aunque dispersa y fragmentada - aborda cuestiones de fundamento: ¿qué es la literatura? ¿Cuál es su función? El análisis de sus aforismos, entrevistas y correspondencia permite reconstruir un sistema orgánico de pensamiento en el cual proponemos distinguir dos funciones complementarias de la literatura, que concibe como arte y como diversión inteligente que permite ver más allá de la apariencia. Aunque su obra es coetánea a la generación del 70 defiende, como otros autores, planteamientos alternativos al de los llamados novísimos.

Palabras clave: Carlos Pujol (1936-2012). Poética explícita. Pensamiento literario. Función de la literatura. Aforismos.

Abstract: In order to contribute to the understanding of the literary thought 
of the poet, novelist, critic and translator Carlos Pujol (1936-2012), we analise three primary sources of his poetics where he explicitly formulates his literary ideas - though scattered and fragmented - responding to fundamental questions such as, What is literature? What is its function? The analysis of his aphorisms, of interviews and correspondence allows us to reconstruct an organic system of thought where there are two complementary functions of literature, viewed both as art and as intelligent fun, allowing us to see beyond appearances. Even if his work is coetaneous with the generation of the 70's he adopts, like other authors, an approach different from that of the so-called novísimos.

Key Words: Carlos Pujol (1936-2012). Explicit Poetics. Literary Thought. Literature's Function. Aphorisms.

\section{INTRODUCCIÓN ${ }^{1}$}

La necesidad de definir y caracterizar las generaciones literarias - como la del 50 o la del 70 de la literatura española del siglo XX- no debería hacer olvidar las limitaciones inherentes a este tipo de categorías históricas, que pueden contribuir a hacer invisible — por inclasificablela obra de un autor. De esta ordenación generacional se derivan dos paradojas sobre el poeta, novelista, traductor y crítico literario Carlos Pujol (1936-2012). En primer lugar, por edad le correspondería la llamada generación del 50 que agrupa a los autores nacidos entre 1924 y 1938 que comenzaron a publicar en los años 50 y llegaron a su madurez en los años 60. Sin embargo, el primer poemario de Pujol es de $1987^{2}$, de modo que incluso es posterior a las primeras obras de la siguiente generación,

\footnotetext{
${ }^{1}$ Agradezco a Manuel Longares, Laureano Bonet, Joaquín Moreno Pedrosa, Santiago Bertrán y Ángela Navarro su atenta lectura de una versión previa de este trabajo.

${ }^{2}$ Unos años antes, con cuarenta y tantos, debuta como novelista (La sombra del tiempo, 1981), por entonces "era ya un prestigioso ensayista y crítico, un traductor extraordinario y un editor veterano” (Ródenas de Moya, 2017: 17).
} 
la del 70, formada por los escritores nacidos entre 1939 y 1953. Por otra parte, si bien sus diecisiete poemarios son coetáneos a la producción de esta generación, la tendencia a considerar que la poética de los llamados novísimos es la definitoria de toda su generación dificulta vincularlo a ella y dar visibilidad a otros planteamientos. En este sentido, Moreno Pedrosa (2017) advierte que en estudios recientes de un modo u otro se termina por extrapolar a toda la generación del 70 los planteamientos iniciales de un determinado grupo, el de los novísimos y los poetas afines a ellos ${ }^{3}$. Por su parte, tras analizar la poética de Antonio Carvajal, Miguel d'Ors y Eloy Sánchez Rosillo constata que:

paralelamente a la concepción "novísima" de la poesía, de inspiración post-estructuralista y deconstructivista, en la generación del 70 se da otra visión del hecho literario, que enlaza con las poéticas de la generación del 50, los poetas de la posguerra, del 27 y de toda la tradición anterior. Según esta visión, el lenguaje se referiría inevitablemente a la realidad, si bien de modo imperfecto, y la creación poética obtendría de ésta los materiales básicos para llevar a cabo su artificio. Además, para Carvajal, d'Ors y Sánchez Rosillo, la poesía no sólo es una actividad que procede de la vida, sino que también puede ejercer su influjo sobre ella. Los tres autores tienen una concepción trascendente del quehacer poético, y le reconocen un poder transformador de la realidad (Moreno Pedrosa, 2017: 378).

\footnotetext{
${ }^{3}$ Vid., por ejemplo, Pérez Parejo (2002), Lanz (1997, 2011) e Iravedra (2010). Lamentablemente, "un efecto perverso que hemos venido sufriendo en estos últimos cien años ha sido la pretensión de que todo escritor debe estar alineado - y alienado - en un grupo, representar una tendencia o una escuela, ser lo que llaman "la voz de su generación"” (Pueo, 2017: 255).
} 
Como veremos, la poética de Carlos Pujol sintoniza plenamente con esta concepción trascendente de la poesía y, en este sentido, es otro ejemplo de autor disidente del planteamiento oficial de la generación del 70 , con un perfil totalmente singular. Este inclasificable sabio clandestino, escritor casi secreto y solitario corredor de fondo - como se le ha llamado a veces - es autor de cincuenta obras de creación (poesía, narrativa, aforística, ensayo y crítica literaria) y unas cien traducciones, la mayoría del francés (Ronsard, Joubert, Stendhal, Balzac, Baudelaire, Gautier, Proust, Simenon, entre otros) y del inglés (Shakespeare, Marvell, Defoe, Browning, Dickinson, Henry James, etc. $)^{4}$. De su intensa frecuentación de la literatura francesa y anglosajona como crítico y traductor se deriva una tercera paradoja, y es que, si bien escribe en castellano, su diálogo con estas tradiciones literarias es más relevante incluso que con la propia tradición literaria española. Se apropia y fusiona tradiciones en una síntesis personal que es a la vez supranacional y en cierto sentido atemporal:

Encontrar un sitio adecuado en la historia de la literatura a Carlos Pujol es tarea ardua y arriesgada. [...] Sería quizá posible definirlo como una esencia de la mejor prosa en Europa desde el siglo XVIII francés hasta el XX hispanoamericano, pasando por el romanticismo y el simbolismo como a través de un baño empapado de sustancias tradicionales (Horia, 1986).

No debería extrañar, pues, que Pujol se sintiera escribiendo en tierra de nadie y siendo de muchos sitios a la vez:

Afortunadamente, la cultura se resiste a ser nacional, todos somos híbridos, aunque en mi caso tal vez lo sea un poco más.

\footnotetext{
${ }^{4}$ Para una visión de conjunto de la obra de este autor, vid. el monográfico que recientemente le ha dedicado la revista Ínsula (Vallès-Botey y Gilabert, 2017).
} 
Quiero decir que lo de ser español habría que matizarlo: las literaturas francesa y anglosajona (también otras, pero no de un modo tan profundo) me han enseñado e influido muchísimo más que la literatura castellana, con lo cual resulta que estás escribiendo en una especie de tierra de nadie, sin sentirte de ningún lugar concreto, o siendo de muchos a la vez (2008a).

Por su experiencia como escritor y por su extenso conocimiento de la tradición, cabe esperar de Carlos Pujol una visión madura y matizada, propia y singular del hecho literario. Como primera aproximación, nos proponemos exponer y articular su pensamiento sobre qué es la literatura y cuál es su función. Para ello presentaremos en el apartado siguiente las fuentes empleadas y, en los apartados sucesivos, su concepción de la literatura desde dos vertientes complementarias: la estética (la literatura como arte) y la lúdica y cognitiva (como diversión inteligente).

\section{FUENTES PARA EL ESTUDIO DEL PENSAMIENTO LITERARIO DE CARLOS PUJOL}

El pensamiento literario de un autor tan polifacético como Pujol se halla disperso en fuentes de muy diversa índole. Por una parte, se encuentra de un modo implícito en su narrativa y obra poética, donde es posible ver cómo lo lleva a la práctica. Por otra parte, lo aplica en su tarea de crítico literario, tanto en sus ensayos sobre literatura francesa ${ }^{5}$ como cuando pondera la obra de escritores franceses y anglosajones en recopilaciones de artículos y reseñas ${ }^{6}$. En todas estas obras - y en cientos de prólogos, reseñas y artículos que todavía no han sido reunidos en un libro - se puede

\footnotetext{
${ }^{5}$ Se trata de Voltaire ([1973] 1999a), Balzac y La comedia humana ([1974] 1983a), Abecé de la literatura francesa (1976) y Leer a Saint-Simon ([1979] 2009b). También publicó una casi desconocida pero extensa historia de la literatura universal (Pujol, 1967).

${ }^{6}$ Vid. La novela extramuros (1975), El espejo romántico (1990), Victorianos y modernos (1997) e Itinerario francés (2000).
} 
deducir el pensamiento literario de Pujol a partir de sus juicios sobre los autores reseñados y sobre la historia de la literatura en general.

Disponemos además de otras fuentes que pueden y deben orientar la comprensión de sus ideas literarias. Se trata de textos en los cuales Pujol expone abiertamente su poética (aunque de forma fragmentada y asistemática): sus libros de aforismos y las entrevistas que concedió a la prensa, así como su correspondencia personal ${ }^{7}$. El análisis de estas fuentes primarias y directas de su poética explícita es necesario como fundamento y guía de la interpretación de su poética implícita.

Carlos Pujol recopiló todos sus aforismos en Cuadernos de escritura (2009a), que contiene los dos libros de aforística publicados con anterioridad - Cuaderno de escritura (1988a), Tarea de escribir (1998)y también el hasta entonces inédito Memorándum. Palabras para escribir. Además de los aforismos, en Cuadernos de escritura pública breves artículos sobre la literatura y la vida literaria. Como señala en el prólogo, se plantea por qué se escribe, qué se escribe y cómo se escribe, por lo que estas obras son el punto de partida esencial e ineludible para conocer las ideas literarias de Pujol tal y como él las publicó: mediante aforismos

\footnotetext{
${ }^{7}$ La dispersión y "el fragmentarismo suele ser la tónica general de las poéticas de autor recogidas a menudo en cartas, entrevistas, conversaciones, notas sobre su labor de creación, diarios íntimos, etc." (Rubio Montaner, 1990: 190). Otros géneros frecuentes de las poéticas explícitas son "los prólogos o epílogos a obras propias o ajenas, en general la producción teórico-crítica del autor, sectores de sus escritos memorialísticos, de sus cartas, de las entrevistas concedidas, de las conferencias" (Casas, 2000: 214). Entre las cuestiones abiertas en relación a las poéticas explícitas cabe mencionar —además de la diversidad terminológica: poéticas de autor, autopoéticas, poéticas explícitas, etc.- , la discusión sobre la pluralidad tipológica que se admite en el seno de la categoría (por ejemplo, si contiene textos literarios) y si constituyen o no un género textual. Así, Casas (2000: 215) asume la inclusión de textos metaliterarios (como un poema sobre el hecho poético) y considera la clase de textos autopoéticos como "un dominio borroso en el que se incorporarían una serie abierta de manifestaciones textuales cuando menos convergentes en un punto, el de dar paso explícito o implícito a una declaración o postulación de principios o presupuestos estéticos y/o poéticos que un escritor hace pública en relación con la obra propia bajo condiciones intencionales y discursivas muy abiertas" (2000: 210). Por su parte, Badía Fumaz (2018a, 2018b) excluye los textos literarios y defiende que las poéticas explícitas constituyen un género textual propio.
} 
que son como pinceladas magistrales de un cuadro que hay que intuir. Se trata de sutiles pensamientos que no están insertos en un argumento elaborado y que a menudo expresan paradojas, provocaciones e ironías. Así, en relación al estilo literario, afirma que "sin medida no hay estilo, y sin desmesura tampoco" (Cuadernos de escritura — en adelante CE—: 66) y sobre la teoría literaria sostiene que "uno tiene muchas teorías sobre la literatura, pero todas contradictorias" (CE: 134).

En cuanto a las entrevistas al escritor publicadas en la prensa son unas veinte y están fechadas entre 1982 y 2011. Gracias a las preguntas de los entrevistadores encontramos respuestas a cuestiones que el lector de la obra pujoliana se plantea. Por ejemplo, en una de sus primeras entrevistas, el también escritor Enrique Badosa le pregunta sobre la razón de ser de las frecuentes referencias culturales que a menudo de forma sutil impregnan novelas como La sombra del tiempo:

- ¿Se considera, pues, un narrador al que se pudiera calificar, no tildar, de culturalista?

- Hay unas palabras de Eliot, en uno de sus ensayos que pueden constituir la mejor respuesta. Dicen así: "Para muchas personas, la literatura es vida y la vida es literatura” (Pujol, 1983b).

Finalmente, de su correspondencia personal analizaremos las cartas que dirigió a su amigo el juez y editor Miguel Ángel del Arco Torres ${ }^{8}$. El motivo de la correspondencia fue la petición de consejo y asesoramiento por parte del juez para escribir sus memorias, que finalmente se publicaron con un prólogo de Pujol (2014). Entre agosto de 2007 y enero de 2012, nuestro autor revisó los diversos estadios de redacción de estas memorias y dirigió a Del Arco más de setenta cartas con correcciones, comentarios y sugerencias, así como criterios de su modo particular de practicar y

${ }^{8}$ Esta correspondencia se puede consultar en el Fondo Personal Carlos Pujol de la Universitat Internacional de Catalunya. 
entender la literatura.

Esta correspondencia permite conocer las ideas literarias de Pujol de puertas adentro, pues expone abiertamente las razones de opciones y criterios que subyacen a sus aforismos y ensayos. En este sentido las cartas complementan los escuetos aforismos. Así, por una parte está este tajante aforismo antididactista: "Los peores enemigos de la literatura son la sociología y la moraleja, la representatividad y el mensaje. Salvados estos escollos se puede empezar a hacer algo" (CE: 26). Por otra parte, Pujol explica por carta a su amigo los motivos de su precaución contra la literatura abiertamente pedagógica: “en fin, el afán didáctico nos puede, a mí también me pasa, pero procuro tener en cuenta que la denuncia es mucho más eficaz si se hace indirectamente y con humor. Si se consigue que leyéndonos los lectores sonrían ya son nuestros" (Carta a Miguel Ángel del Arco, 5/5/10; a partir de aquí, citaremos esta correspondencia con las siglas $C O$ seguidas de la fecha de redacción).

De acuerdo con nuestro objetivo, hemos buscado en estas tres fuentes documentales las reflexiones de Pujol en torno a las preguntas sobre qué es la literatura y cuál es su función. Su contestación habrá que tenerla en cuenta tanto para comprender el trasfondo de su obra de creación, como para enriquecer la historia de las ideas literarias de los escritores contemporáneos ${ }^{9}$.

\section{LA LITERATURA COMO ARTE: "TODA LITERATURA DEBERÍA SER OBRA DE ARTE Y NO CONFORMARSE CON MENOS"}

El punto de partida del pensamiento literario de Pujol es su convencimiento de que la literatura, para serlo, debe aspirar a lo más alto - a ser una obra artística: "toda literatura debería ser obra de arte y no

\footnotetext{
${ }^{9}$ Complementamos, en este sentido, las aportaciones de Camacho (2018), Provencio (1988a, 1988b) y Pozuelo Yvancos (2011).
} 
conformarse con menos" $(C E: 17)^{10}$. Una importante consecuencia de este principio y fundamento es su férrea oposición a toda visión utilitaria de la literatura, su resistencia a ponerla al servicio de intereses económicos e ideológicos, o de la vanagloria del escritor. Como veremos a continuación, advierte sobre el peligro de reducir el valor de la literatura a un beneficio o rendimiento inmediato, para resaltar que su esencia en cuanto obra de arte es el estilo.

\subsection{El riesgo de la vida literaria y del utilitarismo}

Carlos Pujol se muestra convencido de que al escritor le conviene estar lo más desprendido posible de la utilidad práctica que pueda tener su obra en términos económicos y sociales. Su tarea consiste en escribir y publicar, y cuanto más se desentienda de todo lo demás, mejor para él. Como editor y jurado de importantes premios literarios, conoció muy de cerca el mundo editorial y llegó a la conclusión de que "la vida en el ambiente literario es casi uno de los peores enemigos de la misma literatura" (Pujol, 1994: 34). Así retrata esa vida literaria que le parece del todo incompatible con dedicarse a la literatura propiamente dicha:

Proyectos, tertulias, chismes de la profesión, premios cuyos ganadores se conocen días antes, críticas elogiosas u hostiles, conferencias, simposios, contratos, agentes y anticipos, politicas editoriales, cifras de venta, traducciones extranjeras, éxitos (la etimología latina quiere decir salida, aunque nunca se aclara de

\footnotetext{
${ }^{10}$ En este sentido se plantea Pujol en una entrevista: "Quien ha pintado un cuadro (sea bueno o malo: esa es otra historia) ha querido hacer arte. ¿Por qué una novela no es una obra de arte? ¿Por qué tiene que reflejar una idea, transmitir un mensaje o divertir? ¿Por qué se descarta tan frecuentemente su carácter de categoría de arte?", y a continuación desvela un referente: "Para mí, Proust es el gran artista de la palabra: convertía en arte todo cuanto tocaba. (...) Proust es el prototipo del novelista artista. El único al que siempre vuelvo, como se vuelve a la casa paterna" (Pujol, 1982a).
} 
qué o hacia qué) y fracasos que para el interesado son injustos (CE: 81).

La literatura, insiste, se reduce en síntesis esencial al hecho de escribir y al hecho complementario de leer (CE: 97), todo lo demás no es más que "un caldo de intereses, vanidades, envidias, modas y quimeras que parecen formar parte de la profesión, como ciertas salsas acompañan inevitablemente determinados platos" (CE: 98). El precio que exige esa vida literaria que tanto deslumbra, advierte, puede ser muy alto: perderse a uno mismo. Por eso es necesario defenderse ante todo aquello que suponga poner la literatura al servicio de intereses económicos, ideológicos o del tipo que sea, y estar alerta de las consecuencias del afán cortoplacista de éxito literario.

3.1.1. El éxito: "La falta de éxito es una bendición de la que uno siempre está inconsolable”

Para Carlos Pujol pretender alcanzar lo que habitualmente entendemos por éxito supone entrar en la rueda de una visión mercantilista de la literatura:

Aspirar a lo que se suele llamar el triunfo y la fama (grandes premios, grandes ventas, sustanciosos anticipos, popularidad, críticas reverentes, etc.) significa participar en la sociedad de consumo, para la cual la literatura es también una mercancía (Pujol, 2004: 79).

Por tanto, considera que no cabe sino elegir entre dos alternativas: o bien optar por la literatura al precio de renunciar a un posible éxito a corto plazo, o bien hacer carrera literaria al precio de sacrificar lo que 
verdaderamente es la literatura. Con palabras de Pujol: "escribir hace la literatura, la vida literaria hace la carrera" (CE: 81). La paradoja, por tanto, es que quien carece de éxito está en mejores condiciones personales para dedicarse verdaderamente a escribir, es decir, a la literatura propiamente dicha. Por eso concluye, en uno de sus memorables aforismos, que "la falta de éxito es una bendición de la que uno siempre está inconsolable" (CE: 51).

Sin embargo, esta renuncia al triunfo inmediato no es por falta de ambición, al contrario, se realiza para ocuparse en escribir la mejor literatura que uno sea capaz y, por tanto, en aras de una obra que pueda merecer reconocimiento a largo plazo. Para que una obra sobreviva el listón debe estar alto, pues - como conocedor de la historia literariabien sabe que "en literatura se es un clásico o no se es nada, se escribe con perennidad o para el olvido" (CE: 24). Su actitud personal ante el éxito y la perdurabilidad se adivina en los elogios a su admirado Joseph Joubert (1754-1824) — pensador francés cuya valiosa obra solo se publicó póstumamente- en los cuales reconocemos a Pujol mismo:

No es un ansioso, ni tiene nada de fanático, no se empeña en triunfar. [...] Digamos que esta actitud, que está entre la humildad y la sensatez, entre la ironía y el desprendimiento, es lo que permite que a la larga si haya tenido supervivencia (Pujol, 2000: 190).

Así pues, por una parte la ambición del escritor debe ser que su obra le sobreviva: "[...] Se escribe / buscando las palabras / que duren escondidas / cuando seáis al fin la letra muerta"11 (Pujol, 2007). Por otra, sin embargo, el escritor no debe obsesionarse con la posteridad, que es un

\footnotetext{
${ }^{11}$ El topos platónico de la "letra muerta" remite al Fedro de Platón, texto de referencia sobre el tema de la memoria y el olvido vinculados a la escritura (Pozuelo Yvancos, 2006: 73-75).
} 
fantasma absurdo de algo que aún no ha nacido (CE: 140). Incluso, por si la posteridad pudiera ser la última trampa del utilitarismo, recomienda desprenderse también de ella y escribir pensando en un lector ideal: "Escribir no para hoy ni para la posteridad, sino para los de ayer, para un lector ideal que ya no existe. Es la única salvación literaria, porque es el único camino ajeno al utilitarismo" (CE: 61).

Apuesta por renunciar al éxito inmediato - que nuestra sociedad de consumo tan caro hace pagar al escritor que lo persigue - y por escribir sabiendo que "galardones vendrán o se perderán por el camino, pero no forman parte del oficio ni de la condición de escritor; en esta cuestión, el solitario de Carlos no tiene dudas" (Longares, 2017: 23). Opta por escribir solo con la certeza de que "es imposible que un buen escritor no encuentre en algún momento un puñado de buenos lectores. Estos, junto con su ilusión y su arte, ya bastan" ( $C E: 67)$. Hasta qué punto se empeña en estar lo más desprendido posible de todo beneficio se puede intuir en su reacción ante los halagos de su amigo Del Arco al libro de poesía que por entonces había publicado Pujol:

Uno escribe como quien echa moneditas a un pozo, oye el ruido al caer en el agua y después un silencio, no hay por qué esperar más ni desear más. Sólo con que a un lector le haya interesado lo escrito, haya podido incorporarlo a su personalidad, es más que suficiente, demos por bien empleado el esfuerzo de escribir el libro. Muchísimas gracias por todo lo que me dices, que azara un poco, como siempre las frases elogiosas, y que te agradezco infinitamente (CO, 8/11/11).

3.1.2. Las modas y la crítica: "Modas. Ni inventarlas ni seguirlas"

Seguir una moda literaria - ya sea un género, un estilo o una temática que goza de aceptación entre los lectores contemporáneos- es, 
para Pujol, un camino completamente equivocado. Su criterio en este tema es tajante: "Modas. Ni inventarlas ni seguirlas" (CE: 132). Este rechazo a lo que podría parecer un atajo para alcanzar reconocimiento y aceptación se fundamenta en su convicción de que implicaría perder lo más valioso que tiene un escritor: su voz personal. Mímesis y autenticidad son valores antagónicos, pues escribir miméticamente, a la moda, es un indicio de que se renuncia a la propia voz: "Imitadores de Tal o Cual, fantasmas voluntarios de la mediocridad, con la invencible vocación suicida de ser otro" (CE: 55).

Para ilustrar esta máxima, Pujol compara dos pintores holandeses: Van Gogh, que a su muerte sólo había vendido un cuadro, y Alma-Tadema, que era:

la firma más cotizada de la Inglaterra victoriana, le hicieron Sir y ganó una fortuna con sus pinturas de griegos y romanos [...] su éxito consistió en fingir que aquello era suyo, personal, cuando sólo era un espejo complaciente. En cambio, Van Gogh no podía dejar de pintar como Van Gogh, y así le fue. No llevaba la contraria porque sí, por esnobismo, sino porque sólo llevando la contraria era Vincent Van Gogh, de otro modo no era nadie, no podia pintar (CE: 92).

Estas convicciones y actitudes son fruto de su experiencia como escritor, crítico y editor, y de su conocimiento de los vaivenes e incongruencias del éxito y el fracaso literario de autores de todas las épocas. Personalmente optó por estos principios sabiendo de antemano lo que podía ganar y perder con ellos. Fue sin duda un escritor a contracorriente y es todavía un desconocido para la gran mayoría de los lectores contemporáneos. Sin embargo, es reconocido y aclamado por los que conocen su obra, que "rezuma autenticidad y criterio personal: es un escritor que no renuncia a sí mismo y desdeña las modas y los 
conformismos" (Horia, 1986).

En cuanto a los juicios de la crítica literaria, Pujol aconseja distanciarse y relativizar sus opiniones, especialmente cuando son favorables. Sobre este tema, su ironía se acentúa hasta casi la parodia, pero nadie le puede contradecir cuando advierte que "por mucho que elogien lo que hemos escrito no conseguirán mejorarlo en nada" (CE 56). La brújula del escritor es su propio talento, de modo que lo más sensato es hacer oídos sordos a los cantos de sirenas, tan agradables de oír, y reírse del consuelo que dan: las críticas favorables, afirma, "son como los chupetes para los bebés, tranquilizan y confortan" (CE: 141).

\subsubsection{El peligro del didactismo: "La enseñanza cuanto más oculta mejor"}

Poner la literatura abiertamente al servicio de la difusión o defensa de una causa es, en realidad, una forma de utilitarismo y de perder de vista que la esencia de la literatura es su condición de obra de arte. Hacer literatura para adoctrinar le parece a Carlos Pujol un contrasentido en toda regla, pues considera que "escribir para dar lecciones de algo es como echar a correr con una mochila llena de piedras" $(C E 138)^{12}$. En este sentido es significativo que en el prólogo que escribe a las memorias del juez Miguel Ángel del Arco, Pujol celebra que su autor haga hablar a los hechos, sin dar explícitamente lecciones al lector:

Con tacto y una fina sensibilidad, rehúye las moralejas; no quiere teorizar, dejando que los hechos hablen por si mismos [...]. No

\footnotetext{
${ }^{12}$ En este punto Pujol coincide con Nabókov, quien "muchas veces había proclamado su aversión al realismo y a toda variedad de prosa didáctica o utilitarista; detestaba la novela política o sociológica" (Pujol, 1977). Sería interesante explorar la concomitancia del antididactismo de Pujol con el de otros escritores contemporáneos como Juan Benet, Eduardo Mendoza y Javier Marías, que reaccionan contra la hegemonía de la novela social de años atrás.
} 
aspira a demostrar nada, la realidad no se demuestra, sólo se hace visible. Para que entendamos (Pujol, 2014).

Este elogio refleja un criterio de Pujol mismo quien, durante el proceso de revisión de estas memorias, sugiere por carta a Del Arco una y otra vez "evitar el tono explícitamente didáctico, la enseñanza cuanto más oculta mejor, las conclusiones ha de sacarlas el lector a partir de lo que tú le cuentas" $(C O, 6 / 5 / 09)$. Esta afirmación contiene un matiz importante: no se trata de que la literatura no pueda enseñar nada al lector, sino que esa enseñanza debe estar implícita, nunca impuesta como una lección. Se trata de que el escritor sugiera con elegancia y el lector recoja el guante pues "en literatura el escritor debe andar medio camino y quien lee, el otro medio" (Pujol, 1988b). En otra ocasión Pujol felicita a Del Arco por dejar que sea el lector quien — si no es tonto o fanático — deduzca la conclusión de los hechos crudamente narrados en las memorias:

has sabido lidiar muy bien con temas ásperos, difíciles e incómodos [...], que parecian tentar a expansiones personales y moralejas. La manera distanciada hace que ganen en convicción, se exponen hechos para que el lector saque sus consecuencias (si no lo hace es que es tonto o fanático, allá él, porque en el texto se le dan todos los elementos para llegar a una conclusión) (CO, 1/2011).

Así pues, la clave para evitar el moralismo es referir los hechos y dejar que hablen por ellos mismos al lector receptivo. En una ocasión menciona a Azorín como argumento de autoridad de la primacía de los hechos sobre las valoraciones explícitas del autor: "Te copio un buen consejo de Azorín [...] 'Llegan más adentro en el espíritu, en la sensibilidad, los hechos narrados limpiamente que los enojosos e inexpresivos superlativos"' $(C O$, 
s.f.). En otra carta se alegra por unos capítulos de Del Arco que "son claros, divertidos, amenos y dicen muchas cosas como sin darle importancia, aunque el lector comprenderá que la tiene" (CO, 23/4/10).

Pujol defiende este criterio antididactista de un modo más genérico cuando subraya que una novela ha de sugerir pero no debe dar ninguna lección. "Soy totalmente contrario — afirma — a la novela de tesis" (1999b: 34), es decir, contrario a la novela abiertamente didáctica, concebida y diseñada al servicio de una teoría o de una causa, por noble que sea. Cuando acusa a la sociología y la moraleja de ser los peores enemigos de la literatura $(C E: 26)^{13}$, defiende el hecho literario de su instrumentalización $\mathrm{y}$, a la vez, pone humildemente los pies en el suelo a quien se considere autorizado a dar lecciones. Por muy convencido y seguro que se sienta el autor, no debe olvidar que "toda novela es la averiguación de una verdad que nunca se llega a descubrir del todo. Los autores que son tan listos que sólo aspiran a demostrar lo que creen verdadero deberían abstenerse" ( $C E$ : 69).

En cambio, cuando la literatura no olvida lo que debería ser, arte y diversión inteligente (cf. Apartado 4), es capaz de hacer pensar al lector. La paradoja es que Pujol, empeñado en no dar explícitamente sermones ni lecciones a sus lectores, logra de ellos complicidad y agradecimiento:

Es uno de esos contados escritores a los que acudimos en busca de lectura, es decir, de entretenimiento, y acabamos saliendo cargados de sosiego, de ironía y de clarividencia. Uno de esos escritores que nos rearman ante la vida sin ponerse infulas de filósofo ni toga de maestro (Romera, 1994).

\footnotetext{
${ }^{13}$ También como crítico literario mantuvo una perspectiva personal y desapegada de teorías: "nunca hizo caso de ninguna moda metodológica, ni psicoanálisis, ni estructuralismo, ni marxismo. Incluso con Roland Barthes, al que había leído y al que había traducido, mantenía sus distancias" (Puig, 2017: 27).
} 


\subsection{La literatura como estilo: "EI verdadero escritor se juega la vida en cada palabra"}

El estilo es condición sine qua non de la literatura en cuanto obra de arte. Que un texto sea artístico no depende de lo que dice, sino de cómo lo dice: del estilo. Puesto que la literatura es, en esencia, el estilo, no hay detalle sin importancia: "el verdadero escritor se juega la vida en cada palabra" (CE 17), de modo que no se puede permitir el lujo de que una sílaba sobrante o una asonancia innecesaria estropeen la música (Pujol, 1988c). Aspirar a la condición de obra de arte, requiere un esfuerzo tenaz.

Una novela tiene que aspirar a ser una obra de arte. Hay que estar atento a todos los detalles: corregirla y reescribirla varias veces, si es posible, pues de esa forma siempre mejora (Pujol, 1988c: 26).

Como criterio general, sostiene que pulir el estilo consiste en lograr mayor naturalidad en la expresión, pues "el aire de naturalidad (que a veces se consigue con mucho trabajo) es importante, no transmitir al lector una sensación de trabajoso y elaborado" (CO, 14/2/11). La naturalidad es, por tanto, fruto de una sensibilidad delicada y de un empeño incansable de revisión al que a menudo alude Pujol en sus cartas a Del Arco:

No es perder el tiempo limar frases, buscar la forma más clara y natural, en eso estamos (CO, 14/1/10).

La solución siempre es lo más sencillo, lo más claro, lo más expresivo y natural, y - si es posible-lo más correcto (CO, 17/12/09).

Cuando una corrección pule la frase, la hace más limpia, más directa, bienvenida sea, yo soy un maniático de esas cosas, pero 
sin complicar y tergiversar el estilo $(C O, 17 / 12 / 09)$.

Para lograr esa difícil naturalidad del lenguaje y como modelo estilístico de prosa, Pujol sugiere tener en cuenta la de Baroja por su sencillez y expresividad:

Antes de sentarse a escribir, leer unas páginas por ejemplo de Baroja, que es un modelo de expresión clara, sencilla y eficaz. Por ejemplo, de las Memorias, que es además un libro divertidísimo. Hay escritores más de "arte y ensayo", como Valle-Inclán y en cierto modo Azorín (con los antiguos hay que vencer la distancia que impone el tiempo), pero Baroja es modélico en su manera llana y expresiva de contar las cosas (CO, 6/5/09).

Recomienda también no perder de vista la lengua hablada ( $C O$, 17/12/09) y, por supuesto, huir del barroquismo, pues el "exceso de adorno traiciona" (CE: 59). Naturalidad no es pobreza sino mesura — "las palabras, nuestro tesoro. Ni tacañería ni despilfarro" (CE: 131) — con el imposible equilibrio de mezclar con criterio armonioso locura y medida (CE: 18). La práctica de estos criterios sobre el estilo, hace que su obra destaque por un "lenguaje preciso y contenido, sin estridencias, en el que incluso los diálogos, sin perder fluidez ni verosimilitud, se mantienen dentro del registro medio culto del lenguaje" (Senabre, 2008: 20).

Si bien el valor estético es elemento consustancial a lo literario, la función de la literatura va más allá del goce estético y, como veremos a continuación, conlleva el deleite en un sentido más amplio. 


\section{LA LITERATURA COMO DIVERSIÓN INTELIGENTE: "HACER LIBROS DIVERTIDOS PERO SECRETOS, ESTA ES LA FÓRMULA"}

Para Carlos Pujol la literatura tiene una función lúdica ineludible: divertir noblemente, inteligentemente, es decir, ser capaz de "decir al lector algo serio divirtiéndole y haciéndole sonreír" (CO, 24/2/09) ${ }^{14}$. No hay dispensa posible de esta función básica de la ficción, pues "el aburrir es, literariamente, un pecado sin remisión” (Pujol, 1988c: 26). Con el estilo tajante propio de la aforística, Pujol invita irónicamente a cambiar de ocupación a quien opte por aburrir al lector:

Uno de los fines primordiales de la literatura es divertir al lector, con la exigencia más alta que se quiera, pero divertirle. Si a uno le da igual o prefiere el aburrimiento, que se dedique a crítico literario o a teórico socialista (CE: 69).

Esta defensa de la función lúdica de la literatura no es una apuesta por la superficialidad, sino una forma de respeto al lector. Este principio lleva a Pujol, en su ejercicio de la crítica literaria, a celebrar que Llorenç Villalonga sea "fiel al principio de que el escritor bien educado nunca ha de aburrir al prójimo, sino que ha de divertirle inteligentemente sin darse importancia" (1971). En cambio, se mofa de quien en lugar de divertir al lector prefiere parecer sublime: "Si los escritores se preocuparan más de ser entretenidos que de parecer sublimes, todo eso saldríamos ganando" (CE:57).

¿Con qué recursos cuenta el escritor para lograr que la literatura

\footnotetext{
14“'Los teatros — afirma Joseph Joubert — han de divertir noblemente, pero sólo han de divertir. Querer hacer de ellos una escuela de moral es corromper a la vez la moral y el arte" (1995: 74). Pujol, gran admirador del pensador francés, es su primer traductor al castellano.
} 
sea una diversión inteligente? El humor, la ironía, la sorpresa y el estilo indirecto de narrar son recursos habituales de Pujol para hacer sonreír al lector y lograr su complicidad.

En primer lugar, en cuanto al humor en general (como hiperónimo de ironía), Pujol (1983b) considera que es algo consustancial a la misma idea de novela y que aporta una mirada lúcida y humanizadora de la realidad:

El humor es la sal de la vida, y, claro, también de la literatura. No creo que haya gran literatura sin humor, y traer aqui el ejemplo del Quijote sería una obviedad. [...] Humaniza, siempre que sepamos que el humor bien entendido empieza por uno mismo, descubre el modesto envés de lo altisonante (Pujol, 2008a).

La ironía es herramienta clave para desvelar ese "modesto envés de lo altisonante", pues — como destaca Ballart (1994: 381) — es vacuna contra el solipsismo y la gradilocuencia. La de Pujol es una ironía inteligente y sutil, de corte británico, que arrastra al lector a un estado de constante carcajada silenciosa. La tendencia de la ironía a jugar con lo real y lo aparente (Ballart, 1994: 375) es clave para relativizar lo conocido y acceder a lo ignoto. Pujol pone conscientemente la ironía al servicio de la comprensión de la verdad oculta tras las apariencias:

Tengo una gran propensión a la paradoja y a la ironía. Procuro evitar que sea una ironía al servicio de algo y sobre todo que no esté a mi servicio. Ambas permiten un acercamiento a unas zonas de verdad que quedan bastante oscuras (Pujol, 1984).

No se trata, por tanto, de una ironía vacía de significado, insustancial, frívola, sino una capaz de enriquecer al lector con alguna 
luz sobre él mismo (“divertir así es algo muy serio" CE 133). Reacio a la grandilocuencia — destaca Longares (2017: 22) — Pujol ofreció a través de dos instrumentos indirectos, como la ironía y la paradoja, las claves para entenderlo y leerle.

La sorpresa es otro elemento clave. Puesto que la literatura ha de ser una diversión inteligente, sutil, cuando le parece que un texto que revisa es demasiado previsible, Pujol aconseja replantear esas páginas:

Un elemento importantísimo para escribir es la sorpresa, sorprender al lector con lo que se cuenta o la manera como se cuenta, siempre vigilando con la ayuda del sentido común para no caer en la extravagancia gratuita. Y aqui sorpresas hay muy pocas, casi todo es previsible, más bien didáctico y plano (CO, 13/4/10).

Finalmente, el método indirecto de narrar es otro recurso empleado por nuestro autor para evitar el peligro de aburrir al lector. Llama método indirecto a un modo de narrar que se propone expresamente "dejar las cosas a medio decir, nunca aplastar al que lee con una explicación o descripción completas" $(C E: 20)^{15}$. Se trata pues de sugerir, insinuar, crear

\footnotetext{
${ }^{15}$ Sería interesante explorar la relación entre este principio y la teoría del iceberg o de la omisión de Hemingway, según la cual en una narración la parte omitida comunica más fuerza al relato, y le da al lector la sensación de que hay más de lo que se le ha dicho. Pujol - traductor y biógrafo de Hemingway - afirma en una entrevista que "fue uno de los que enseñó a escribir de manera concisa y coloquial" (1999c). Agradecemos a Laureano Bonet esta sugerencia. Otro referente al que también admira Pujol es Henry James, maestro de la "literatura no de reflejo directo sino de rodeo metafórico, de medias palabras, de cosas no dichas", del "arte de no decir diciendo" (Pujol, 1997: 15, 29). También es significativo que Pujol destaque de Kipling "su arte de narrar, siempre eficacísimo, diciendo sólo lo justo y reservándose zonas de misterio que hay que mantener en la penumbra y que conocemos por el modo sutil con que se aluden discretamente o se omiten. Kipling sabía muy bien que en un buen relato lo que no se dice puede contar más que todas las explicaciones" (2008b).
} 
sombras y ambigüedades, "dejar espacios libres para que cada lector los llene a su manera" (CE: 141). Se propone lograr la implicación del lector interpelando a su imaginación e inteligencia, para ello "sólo existe un buen método, el indirecto. Decir las cosas cara a cara es el suicidio del escritor" (CE: 14). El resultado es un modo de escribir elíptico (Ayén, 2003), una forma sinuosa de contar las cosas (Longares, 2017: 22), una manera oblicua, nunca directa, sutil, velada, de contarnos la realidad (Trapiello, 1989: 35).

En una sentencia de nueve palabras sintetiza su apuesta por la literatura como diversión inteligente: "Hacer libros divertidos pero secretos, ésta es la fórmula" ( $C E$ : 49). De acuerdo con lo que hemos visto, son libros "divertidos pero secretos" porque están impregnados de ironía, porque sorprenden al lector y le interpelan, porque le sugieren sutilmente lo desconocido. El lector no puede menos que agradecer estos principios literarios, y el crítico también: "No hay página suya que no nos haga sonreír, atento su autor al impagable principio de enseñar deleitando" (Trapiello, 2017: 16).

Entender la literatura como arte y como diversión inteligente es una meta verdaderamente ambiciosa. Supone asumir el propósito de proporcionar un goce que es a la vez un placer estético, emocional e intelectual. "La literatura — afirma Pujol — es un condensado de fantasía, humor, misterio, con un soporte exigente de palabras (1985: 27). La función estética ("el soporte exigente de palabras") es inseparable de la lúdica ("humor y misterio") y también, como veremos a continuación, de la capacidad de la literatura de hacer soñar y crear — mediante la imaginación y la fantasía - una nueva realidad que consuela y permite comprender la realidad vivida. 


\subsection{La literatura o el sueño de una nueva realidad que ilumina la realidad factual}

En sus reflexiones literarias Pujol se distancia de una interpretación ingenua de la literatura como espejo fiel de la realidad - como pretendía su querido Balzac - y a la vez sostiene la existencia de un vínculo profundo pero sutil entre realidad factual y ficción literaria. Descarta una visión simplona del realismo para subrayar que la materia prima literaria no son tanto los hechos de la biografía del autor como su mundo interior: sus sueños, fantasmas y recuerdos, pues "se escribe para oír la música de dentro" (CE: 14). Desde este punto de vista, cuando una narración se limita a trasladar sucesos vividos es más que probable que carezca de valor literario. Es el problema del que adolecen novelas en las que "se adivinan experiencias personales reflejadas de un modo muy directo, apenas sin novelar, tan apegadas a la realidad que más que literatura son confidencias, lamentos o justificaciones por parte de los autores" (Pujol, 1982b). Hay que tener poca fe - concluye - en esa literatura de "ahora voy y te cuento lo que me pasa" (CE: 75). En cambio, "la buena literatura sale de dentro hacia fuera. Cada uno de nosotros - escritor o no- aloja un tesoro en su interior: un escritor es bueno cuando logra transmitir ese tesoro" (Pujol, 1982a). Al escritor le corresponde escuchar y dar voz a ese mundo interior, pues " "es dentro de uno mismo donde hay que mirar lo de fuera', frase inmortal de Victor Hugo que sentencia a muerte cualquier estética realista" (CE: 63).

A la vez que la literatura se alimenta del mundo interior del escritor, de su imaginación y memoria, es misión suya nutrir ese espacio íntimo: "la función de la literatura es hacernos soñar" (Pujol, 1985) haciendo despertar los propios ensueños:

De la lectura espero que me levante del suelo, como los perros que van a la caza a levantar las bandadas. Sólo aprecio, ahora, la capacidad que tienen los libros de despertar sueños y fantas- 
mas privados. Y eso puede lograrse a veces con la música de una sola frase. Aprecio la capacidad de un libro de devolverme un sueño propio (Pujol, 1982a).

La literatura es ese sueño de libertad inasequible (CE: 18) que aviva nuestros anhelos imposibles y permite materializarlos creando otra realidad más consoladora que la vivida. La nueva realidad colma el deseo de "sustituir lo natural por lo inventado, la realidad por la quimera" $(C E$ : 18), creando una realidad a la propia medida.

Me interesa la literatura como sustitución de la realidad y como arte, como creación de otra realidad personal. Sustituir el orden del mundo en que vivimos por otro orden a mi manera ;no hay empresa más narcisista! (Pujol, 1984: 175).

Con ese nuevo orden o realidad más a nuestro gusto - que se superpone a la realidad factual—, la ficción ofrece un alivio: "La literatura es o debería ser un arte, pero tiene también una función secundaria asistencial: consuela de la vida, primero al autor y luego a los lectores" (CE: 27). El consuelo que brinda la literatura es nada menos que una mejor comprensión del sentido de lo vivido, pues forja "castillos en el aire, lugares soñados donde no se puede vivir aunque completen y den sentido a lo que se vive" ( $C E:$ 9).

Así pues, la nueva realidad que crea la imaginación tiene la función de ayudar a comprender la realidad original: la literatura es "juego o fantasía que transparenta lo que sin ella sería invisible" (CE: 19). Es la clásica paradoja de que la mentira que es fruto de la fantasía nos desvela la verdad que está oculta bajo la apariencia. La ficción literaria sirve para "comprender mejor, valiéndose de mentiras, el fondo de la verdad" y permite "jugar con las apariencias de la realidad, que siempre engañan, 
y sugerir lo que esconden, lo que no se ve" (Pujol, 2004) ${ }^{16}$. El poeta sentencia- está para ver lo que no se ve, para lo que se ve ya está el resto de la gente $(C E: 17)$; por eso la literatura es mucho más que un mero espejo de lo visible, pues permite desvelar lo ignorado por invisible, "sin literatura la realidad perdería su espejo mágico" (CE: 21).

$\mathrm{Al}$ aportar conocimiento sobre lo oculto y escondido, la realidad imaginada tiene un efecto intransitivo, en el sentido de que transforma al autor mismo, le lleva a ser distinto: "Escribir no es hacer, más bien hacerse, completarse con palabras" ( $C E:$ 72). Con este impacto de la literatura en el escritor, se cierra el círculo de la relación entre realidad y literatura: la realidad factual deja su huella en el mundo interior del escritor, del cual se alimenta la literatura, que es ficción que a su vez es capaz de producir una repercusión en la realidad misma del escritor y del lector.

\section{CONCLUSIÓN}

Para una visión más plural y matizada de la generación del 70, se hace necesario dar visibilidad a autores con una poética al margen del planteamiento que desde Castellet se ha considerado paradigmático de esa generación: el de los nueve novísimos. Frente a la duda de este grupo en la capacidad de la poesía de desvelar y aprehender la realidad, Carlos Pujol - como Miguel d'Ors, Carvajal y Sánchez Rosillo, entre otros (cf. Moreno Pedrosa, 2017) - mantiene una concepción trascendente de la poesía y del hecho literario en general, pues la literatura se alimenta de algún modo de la realidad a la vez que incide en ella, en una simbiosis misteriosa y fecunda. Así pues, la confianza en el vínculo entre la realidad y la poesía - que enlaza con la tradición literaria anterior - se mantiene durante la generación del 70.

A la luz de los aforismos, entrevistas y correspondencia de

${ }^{16}$ Cabe destacar que en sus novelas descubrir el engaño de las apariencias suele llevar a una sorpresa grata, pues a menudo se llega a la conclusión de que los personajes son más bondadosos de lo que parecía en un principio. 
Carlos Pujol hemos abordado las decisivas preguntas sobre la naturaleza y la función de la literatura. Se ha reconstruido un sistema orgánico de pensamiento en el que proponemos distinguir dos funciones o dimensiones de la literatura: como arte y como diversión inteligente que permite ver lo que se oculta tras la apariencia. Se trata de vertientes complementarias del hecho literario —artística, lúdica y cognitiva—, que considera incompatibles con el utilitarismo en cualquiera de sus formas. De ahí su prevención contra el mundo literario y la mercantilización de la literatura, contra el ansia de éxito a corto plazo, las modas o el didactismo. Estos son los escollos que debe superar el escritor y así es la literatura tal como Pujol la entiende y la practica. No es poca su ambición. Salta a la vista que el perfil del autor que hay detrás de este pensamiento es un escritor literario que apunta lejos y alto, pues vive la literatura con pasión y entrega.

\section{REFERENCIAS BIBLIOGRÁFICAS ${ }^{17}$}

AYÉN, X. (2003). “Carlos Pujol novela el París previo a la ocupación nazi en Los días frágiles". La Vanguardia, 30 mayo, 40.

BADÍA FUMAZ, R. (2018a). "Hacia una caracterización de las poéticas explícitas. Elementos comunicativos, funciones y tipologías textuales". Castilla. Estudios de Literatura 9, 87-113.

(2018b). "Las poéticas explícitas como género". RILCE 34.2, 607628.

BALLART, P. (1994). Eironeia. La figuración irónica en el discurso literario moderno. Barcelona: Quaderns Crema.

CAMACHO, C. (ed.) (2018). Fuegos de palabras. El aforismo poético

\footnotetext{
${ }^{17}$ Cuando una referencia de los documentos aquí citados está incompleta es porque proceden del archivo personal de Carlos Pujol y en el recorte que guardó no consta la fecha o el medio en que se publicó y no ha sido posible subsanar esa laguna. Se pueden consultar en el Fondo Personal del escritor (Universitat Internacional de Catalunya).
} 
español de los siglos XX y XXI (1900-2014). Sevilla: Fundación José Manuel Lara.

CASAS, A. (2000). "La función autopoética y el problema de la productividad histórica". En Poesía histórica y (auto)biográfica (1975-1999) (Actas del IX seminario internacional del Instituto de Semiótica literaria, teatral y nuevas tecnologías de la UNED), J. Romera Castillo y F. Gutiérrez Carbajo (eds.), 209-218. Madrid: Visor Libros.

HORIA, V. (1986). "La noche más lejana". [Reseña de La noche más lejana. No consta el lugar ni la fecha exacta de publicación. Fondo Personal Carlos Pujol].

IRAVEDRA, A. (2010). El compromiso después del compromiso. Poesía, democracia y globalización: poéticas 1980-2005. Madrid: UNED. JOUBERT, J. (1995). Pensamientos, Carlos Pujol (ed.). Barcelona: Edhasa. LANZ, J. J. (1997). Antología de la poesía española (1960-1975). Madrid: Espasa Calpe.

(2011). Nuevos y novísimos poetas en la estela del 68. Sevilla: Renacimiento.

LONGARES, M. (2017). “Carlos Pujol y el aforismo”. Ínsula 849, 22-25. MORENO PEDROSA, J. (2017). "Lenguaje y realidad: una concepción trascendente de la poesía en la generación española de 1970". Signa. Revista de la Asociación Española de Semiótica 26, 359379.

PÉREZ PAREJO, R. (2002). Metapoesía y crítica del lenguaje: de la generación de los 50 a los novísimos. Cáceres: Universidad de Extremadura.

POZUELO YVANCOS, J. M. (2006). De la autobiografía. Teoría y estilos. Barcelona: Crítica.

POZUELO YVANCOS, J. M. (ed.) (2011). Historia de la literatura española. Vol. 8. Las ideas literarias (1214-2010). Barcelona: Crítica.

PROVENCIO, P. (1988a). Poéticas españolas contemporáneas. La 
generación del 50. Madrid: Hiperión.

(1988b). Poéticas españolas contemporáneas. La generación del 70. Madrid: Hiperión.

PUEO, J. C. (2017). "José María Valverde: notas para un comparatismo irónico". En Comparatistes sense comparativisme. La literatura comparada a Catalunya, Antoni Martí Monterde y Teresa Rossell Nicolás (eds.), 243-259. Barcelona: Edicions Universitat de Barcelona.

PUIG, V. (2017). “Carlos Pujol, crítico literario". Ínsula 849, 25-28.

PUJOL, C. (1967). Literatura universal. En Enciclopedia temática Ciesa, vol. 14. Barcelona: Compañía Internacional Editora.

(1971). "La Lulú”. La Vanguardia, 18 febrero.

(1973). Voltaire. Barcelona: Planeta.

(1974). Balzac y “La comedia humana”. Barcelona: Planeta.

(1975). La novela extramuros. Barcelona: Laia.

(1976). Abecé de la literatura francesa. Barcelona: Planeta.

(1977). "Nabókov: la ironía, el desencanto y el arte". Opinión 41, 16 julio.

(1979). Leer a Saint-Simon. Barcelona: Planeta.

(1981). La sombra del tiempo. Barcelona: Planeta.

(1982a). "Carlos Pujol: La novela y sus sombras". Entrevista de Ana Basualdo. La Vanguardia, 18 febrero.

(1982b). "Fantasía en un entorno cotidiano". La Vanguardia, 23 abril, 33.

(1983a). Balzac y “La comedia humana”. 2a ed. Barcelona: Bruguera. (1983b). "Carlos Pujol, un novelista que se ratifica plenamente". Entrevista de Enrique Badosa. El Noticiero Universal, 21 noviembre.

(1984). "Entrevista". Entrevista de Fernando Valls. Cuadernos de traducción e Interpretación 4, 165-78.

(1985). "Carlos Pujol: 'La función de la literatura es hacernos soñar'”.

Entrevista de E. Crespo. El Noticiero Universal, 25 de junio, 27. 
(1988a). Cuaderno de escritura. Pamplona: Pamiela.

(1988b). "Carlos Pujol: 'Lo que más me interesa de la historia es el misterio del tiempo"". Entrevista de Elena Hevia. $A B C$, 18 febrero. (1988c). "Una novela tiene que aspirar a ser una obra de arte"”. Entrevista de Javier Marrodán. Diario de Navarra, 17 agosto, 26. (1990). El espejo romántico. Barcelona: PPU.

(1994). "Hay muchos escritores chiflados"”. Entrevista de Montserrat Tapias. Diario de Tarragona, 30 octubre, 34-35. (1997). Victorianos y modernos. Oviedo: Nobel. (1998). Tarea de escribir. Pamplona: Pamiela. (1999a). Voltaire. Madrid: Palabra, 2. ${ }^{a}$ ed. (1999b). "Escric per divertir la gent”. Entrevista de Jordi Capdevila. Avui, 12 julio, 34.

(1999c). "La obra de Hemingway va a quedar para siempre entre los clásicos." Entrevista de Gontzal Agote. Gara, 30 de mayo, 54. (2000). Itinerario francés. Pamplona: Pamiela. (2004). “Nadie se queja de no tener talento': Una conversación con Carlos Pujol". Entrevista de Manuel Longares. Quimera 238-239, 77-81. (2007). Poemas. Granada: Comares. (2008a). "Carlos Pujol, escritor". Entrevista de Manuel Ballesteros. Boletín del Colegio de Registradores de España 43 (marzo/abril), 56-58.

(2008b). "Kipling en sus cuentos". ABCD Las artes y las letras 858, 12 julio, 14. (2009a). Cuadernos de escritura. Valencia: Pre-Textos. (2009b). Leer a Saint-Simon. 2a ed. Barcelona: BackList. (2014). "Palabras de un juez". En La audiencia va de caza. Andanzas de un juez de pueblo, Miguel Ángel del Arco Torres (ed.), 7-12. Granada: La Veleta.

RÓDENAS DE MOYA, D. (2017). "Carlos Pujol en sus novelas”. Ínsula $849,17-21$. 
ROMERA, J. M. (1994). “Carlos Pujol o la discreción”. [Texto mecanoscrito del discurso de presentación en Pamplona de Los secretos de san Gervasio y Un viaje a España. Fondo Personal Carlos Pujol].

RUBIO MONTANER, P. (1990). "Sobre la necesaria integración de las poéticas de autor en la teoría de la literatura". Castilla. Estudios de Literatura 15, 183-197.

SENABRE, R. (2008). "Dos historias romanas". El Cultural, 10 julio, 20. TRAPIELLO, A. (1989). "Exageraciones”. Contemporáneos 3, 33-35. (2017). "Carlos Pujol”. Magazine La Vanguardia, 29 enero, 16.

VALLÈS-BOTEY, T. y GILABERT, G. (coords.) (2017). "Carlos Pujol, humanista contemporáneo”. Ínsula 849. Número monográfico dedicado a Carlos Pujol. https://www.insula.es/revista/carlospujol-humansta-contemporaneo [20/04/2018].

Recibido el 30 de abril de 2018.

Aceptado el 5 de julio de 2018. 